\title{
Sugars-eating habits of 405 11- to 14-year-old English children
}

\author{
BY ALLAN F. HACKETT, ANDREW J. RUGG-GUNN*, DAVID \\ R. APPLETON ${ }^{1}$, MARION ALLINSON AND JOHN E. EASTOE \\ Departments of Oral Biology and ${ }^{1}$ Medical Statistics, The University of Newcastle upon \\ Tyne, Newcastle upon Tyne NE2 4BW
}

(Received 29 June 1983 - Accepted 11 November 1983)

1. Between September 1979 and July 1981, 405 northern-English children, initially aged 11-12 years, each recorded all food and drink consumed on five occasions on each of three consecutive days. Sugars and nutrient intakes were calculated using food tables.

2. The average total sugars intake was $118 \mathrm{~g} / \mathrm{d}$ or $21 \%$ of the energy intake and $43 \%$ of the carbohydrate intake; these percentages were similar for both sexes, all social class groups and surveys.

3. Sugars were found to be derived from a variety of food sources with confectionery being the single largest source.

4. Sugars were fairly evenly consumed over the average day with a high amount in foods eaten between meals. Snacks accounted for $65 \%$ of the sugars intake but only $46 \%$ of the energy intake.

5. Sugars intake and snacking therefore seem to have been major components of the eating habits of these children. If dietary changes towards lower sugars intakes are to be achieved a vigorous, informed health education campaign is necessary together with effective labelling of manufactured foods, the development of new products and the modification of some existing ones.

A fall in the dietary sugars intake is generally considered to be desirable (United States Senate, 1977; Department of Health and Social Security, 1978; Royal College of Physicians, 1983) mainly because of the improvements in dental health which are likely to result. However, dietary habits are resistant to change (Chambers, 1981) and a thorough knowledge of the eating and social habits of the individual or target population is essential before practical dietary advice can be formulated. It needs to be established which beneficial habits can be encouraged, which habits need to be discouraged, where improvements might be made without entailing major changes to lifestyle and whether a narrow range of foods is responsible for a large proportion of sugars intake. The first comprehensive study of sugars intake was recently published (Morgan \& Zabik, 1981) and it supplied some of this information for American children. The aim of this paper therefore is to supply similar information for young English adolescents, who are known to be particularly at risk from dental caries. This was achieved using data obtained from a recent 2-year longitudinal survey of over 400 English adolescents, which had the primary aim of relating estimates of individuals' mean dietary intake to their observed dental caries increment.

\section{METHODS}

Between September 1979 and July 1981, over 400 children initially aged 11-12 years recorded their entire dietary intake for three consecutive days on five separate occasions. These children were volunteers from seven schools in the Morpeth, Ashington and Newbiggin area of Northumberland. Each child was asked to record, in a specially designed diary, a description of all foods and drinks taken, the approximate amount consumed in household measures and the time of consumption. They were then individually interviewed on the 4th day when the information provided was verified and enlarged upon. Using the child's description and a variety of calibrated visual aids, a quantitative estimate of intakes

- For reprints. 
was obtained. A note was also made of the combinations of food items consumed simultaneously (labelled 'foods' in this survey) which were aggregated to give the weight of foods consumed per day. Computerized food tables (Paul \& Southgate, 1978) were used to calculate the weight of total sugars and nutrients consumed, and the methods have been fully described elsewhere (Hackett $e t$ al. 1983). These food tables discriminate only lactose from all the other sugars which are totalled together. The term total sugars or sugars in this paper refers to the total of all sugars consumed (including lactose). Table sugar refers to sucrose as used in the home. Further analysis of the types of sugars consumed has not been attempted.

In order to aid the location of the sources of the dietary sugars, the foods were grouped together as follows: (1) confectionery, which included boiled sweets, pastilles, gums, chewing gum, toffees, popcorn, iced-lollies, ice cream, pure chocolate bars, filled chocolates (and bars) and full coated chocolate biscuits; (2) table sugar which consisted almost entirely of refined white sucrose but included the various 'brown' sugars; (3) the soft drinks category which included carbonated and still drinks, e.g. lemonade, cola, cordial and fruit juice but not tea, coffee or milk shakes; (4) lactose which was the total of the sugar lactose consumed in whatever form; (5) the biscuits and cakes category (flour and sugar products) which included all sweet (but not savoury) biscuits, half-coated chocolate biscuits and cakes, including those coated with chocolate; (6) puddings which included milk puddings (e.g. rice), sweet sauces, yoghurts, all flour-based puddings (e.g. pies), tinned and stewed fruits and jellies; (7) fruit which consisted mainly of raw fresh fruit, as dried fruit was excluded from all groups except where it occurred in recipes; (8) the syrups and preserves group which was composed of jam, marmalade, honey, treacle, syrup, lemon curd, marzipan and mincemeat.

The foods consumed were also categorized according to their sugars concentration: a food was defined as the sum of those items of diet (as listed in the food tables) which were consumed simultaneously (e.g. tea plus milk plus sugar or, bread plus butter plus boiled egg). This provides an estimate of the concentration of sugars actually reaching the mouth.

The occupation of each child's father was encoded as social class (Registrar General, 1970). In order to increase the size of the groups analysed, classes I and II were grouped together and labelled 'high' (professional occupations), III was labelled 'middle' (skilled workers) and IV and V 'low' (manual workers). Classes VI, VII and VIII (retired or unemployed, unknown or unclassifiable occupations) were labelled ' miscellaneous', although only small numbers were involved (nine boys, twenty-one girls).

All the information collected was stored in a computer and all analyses were done either using purpose-written programs or, in the case of standard statistical methods ( $t$ test or analysis of variance), using Statistical Package for the Social Sciences (SPSS).

\section{RESULTS}

All aspects of the study were completed by 193 boys and 212 girls or $51.7 \%$ of those asked to volunteer. The three groupings were well represented with 85 ' high', 172 'middle' and 118 'low' social class children. Only one out of the 405 subjects in the study was non-caucasian.

The average daily intakes at each of the five surveys for boys and girls are shown in Table 1. The boys, who increased their energy intake by about $13 \%$ over the 2 years (calculated by regression), consistently consumed more energy than the girls, who increased their intake by only about $7 \%$. The carbohydrate and sugars intake changed in proportion to the energy intake; carbohydrate supplied about $49 \%$ and sugars about $21 \%$ of the energy intake. Of the carbohydrate, sugars accounted for $43 \%$ for both boys and girls.

There were no statistically significant differences in energy, carbohydrate or sugars intake 
Table 1. Mean daily intake of energy, carbohydrate and total sugars for 193 boys and 212 girls at each of the five surveys

(The coefficients of variation were similar for both sexes at each survey and were approximately: energy $22 \%$, carbohydrate $23 \%$, total sugars $33 \%$ )

\begin{tabular}{lcccccc}
\hline \hline Survey... & 1 & 2 & 3 & 4 & 5 & Mean \\
\hline Boys & & & & & & \\
$\quad$ Energy (MJ) & $8 \cdot 9$ & $8 \cdot 9$ & $9 \cdot 3$ & $10 \cdot 0$ & $10 \cdot 2$ & $9 \cdot 5$ \\
$\quad$ Carbohydrate (g) & 274 & 269 & 285 & 300 & 317 & 289 \\
$\quad$ Total sugars (g) & 121 & 118 & 122 & 126 & 133 & 124 \\
Girls & & & & & & \\
$\quad$ Energy (MJ) & $8 \cdot 1$ & $8 \cdot 4$ & $8 \cdot 3$ & $8 \cdot 7$ & $8 \cdot 8$ & $8 \cdot 5$ \\
$\quad$ Carbohydrate (g) & 249 & 254 & 252 & 257 & 268 & 256 \\
$\quad$ Total sugars (g) & 114 & 116 & 109 & 111 & 116 & 113 \\
\hline \hline
\end{tabular}

(weight or percentage) between social classes within each sex (Table 2). The $10 \%$ of subjects (plus 'ties', $n 42)$ with the highest sugars intake $(>159 \cdot 5 \mathrm{~g} / \mathrm{d}$ ) had a higher energy intake than for all subjects and a higher percentage of energy from sugars (25), and of carbohydrate as sugars (49), but only a slightly higher percentage of energy from carbohydrate (51). Twenty-seven of these forty-two subjects were boys, but the social classes were all well represented (ten, seventeen, eight and seven for 'high', 'middle', 'low' and 'miscellaneous' respectively).

The very wide range in mean sugars intake can be seen in Fig. 1, which gives the frequency distribution of daily sugars intake averaged over all $15 \mathrm{~d}$.

There are some small differences in the sources of the sugars intake between sexes and social classes (Table 3 ). The girls derived less sugars from table sugar and lactose, but a higher percentage from confectionery, soft drinks, biscuits, cakes and fruit than the boys. The 'low' social class boys and girls derived a higher percentage of their sugars intake from confectionery and table sugar but a lower percentage from soft drinks compared with ' high' or 'middle' social class boys and girls. The high sugars eaters showed no preferences for the form in which the sugars were consumed compared with all the children.

For all subjects, only $24 \%$ of the total weight of foods consumed had a total sugars concentration of $1 \%$ or less (Table 4) and $19 \%$ of the total weight of foods consumed had a sugars content of over $10 \%$. For both boys and girls there was a significant decrease in the percentage of foods containing over $10 \%$ sugars, as social class became lower (boys: $F_{1,181}=5.38, P<0.05$; girls: $F_{1,188}=8.43, P<0.01$ ). For boys only, there was also a significant decrease in the percentage of foods containing less than $1 \%$ sugars as social class became lower $\left(F_{1,181}=5.08, P<0.05\right)$. The proportion of foods consumed of more than $60 \%$ sugars was very low. In the high sugars eaters, a lower proportion $(20 \%)$ of the foods were of less than $1 \%$ sugars content compared with the other children $\left(t_{60}=3.82, P<0.001\right)$ and more of their foods were in the over $10 \%$ sugars category $\left(t_{47}=5.30, P<0.001\right)$. These $t$ values were calculated by Welch's adaptation of the $t$ test (Bailey, 1981).

Fig. 2 shows the weight of sugars consumed for each half-hour of the day averaged over all $15 \mathrm{~d}$ for all 405 subjects. There were clearly four peak intakes (roughly $07.00-09.00$, $12.00-13.00,16.00-18.00,20.00-22.00$ hours) corresponding to breakfast, lunch, evening meal (tea) and supper. These periods were then used to compile Table 5 which summarizes, on average, the times when sugars were eaten. The evening meal (16.00-18.00 hours) accounted for the highest percentage of daily sugars intake $(21.5 \%)$, and $48.4 \%$ of all sugars were consumed after 16.00 hours. The children's average bedtime was about 22.00 hours 


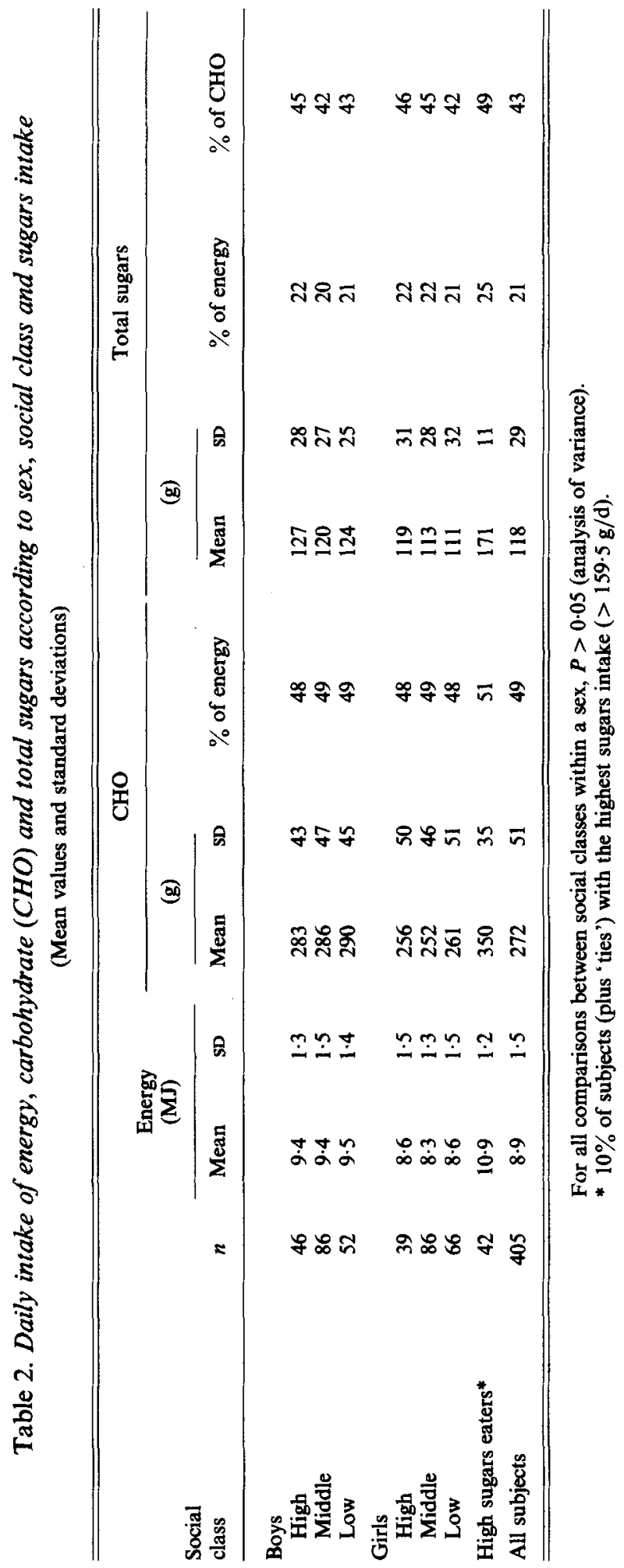




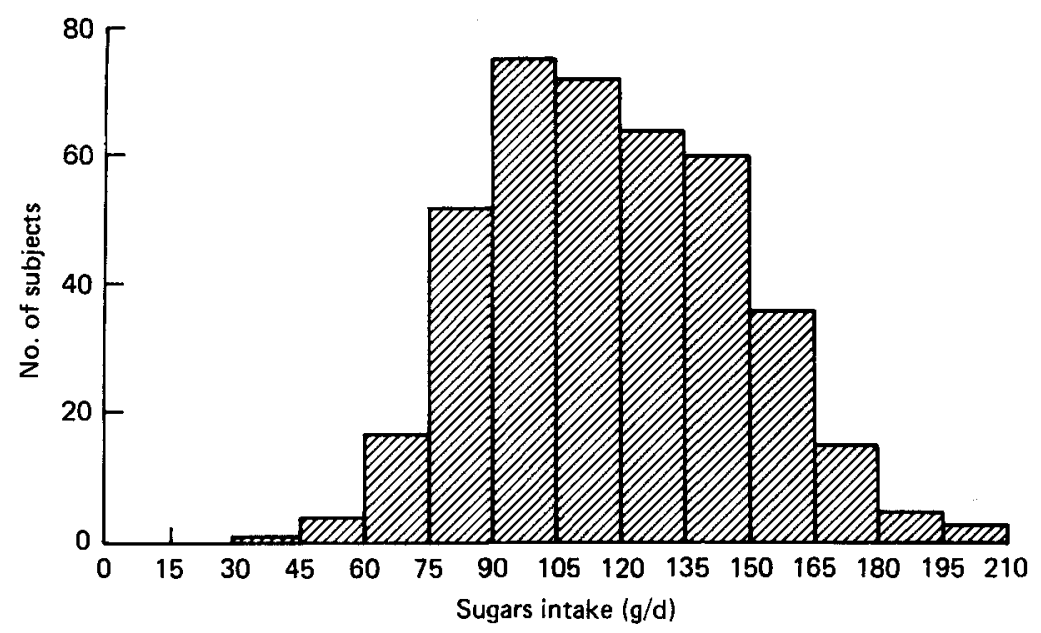

Fig. 1. Frequency distribution of sugars intake/d for 405 children.

Table 3. Mean daily total sugars intake (\%) from each of eight food categories

\begin{tabular}{|c|c|c|c|c|c|c|c|c|}
\hline \multirow{2}{*}{$\begin{array}{l}\text { Sex... } \\
\text { Social class... } \\
n \ldots\end{array}$} & \multicolumn{3}{|c|}{ Boys } & \multicolumn{3}{|c|}{ Girls } & \multirow{2}{*}{$\begin{array}{l}\text { High sugars } \\
\text { eaters* } \\
\text { (42) }\end{array}$} & \multirow[b]{2}{*}{$\begin{array}{l}\text { All subjects } \\
(405)\end{array}$} \\
\hline & $\begin{array}{l}\text { High } \\
(46)\end{array}$ & $\begin{array}{c}\text { Middle } \\
(86)\end{array}$ & $\begin{array}{l}\text { Low } \\
(52)\end{array}$ & $\begin{array}{l}\text { High } \\
(39)\end{array}$ & $\begin{array}{l}\text { Middle } \\
(86)\end{array}$ & $\begin{array}{l}\text { Low } \\
(66)\end{array}$ & & \\
\hline \multicolumn{9}{|l|}{ Food category } \\
\hline Confectionery & 13 & 16 & 19 & 15 & 17 & 22 & 20 & 19 \\
\hline Table sugars & 14 & 18 & 21 & 11 & 16 & 17 & 17 & 17 \\
\hline Soft drinks & 14 & 14 & 11 & 17 & 16 & 11 & 14 & 14 \\
\hline Lactose & 15 & 13 & 13 & 12 & 12 & 11 & 12 & 13 \\
\hline Biscuits and cakes & 13 & 12 & 12 & 14 & 13 & 14 & 12 & 13 \\
\hline Puddings & 10 & 10 & 8 & 12 & 9 & 9 & 10 & 11 \\
\hline Fruit & 4 & 3 & 4 & 6 & 5 & 5 & 4 & 5 \\
\hline Syrups and preserves & 6 & 4 & 3 & 3 & 3 & 3 & 4 & 4 \\
\hline Breakfast cereals & 3 & 3 & 2 & 3 & 2 & 2 & 2 & 2 \\
\hline Other foods & 8 & 7 & 7 & 7 & 7 & 6 & 5 & 2 \\
\hline
\end{tabular}

* $10 \%$ of subjects (plus 'ties') with the highest sugars intake (>159.5 g/d).

and very few children recorded intakes after going to bed. The lunch time (12.00-13.00 hours) peak is remarkable for its brevity whilst the breakfast (07.00-09.00 hours) peak indicates that breakfast is still a popular meal. A consistent $2-3 \%$ of sugars intake was taken after 22.00 hours (suggesting the consumption of sugars close to bedtime in a substantial number of children) but a very low percentage was consumed before 07.00 hours. Most sugars were consumed as snack intakes rather than as meals (Table 6). The snack intakes were poor sources of protein and the boys and girls consumed almost identical amounts of energy as snacks; the boys therefore ate larger meals.

Because a large number of subjects was studied, it is possible that some of the smaller differences between groups, although statistically significant, are of little practical importance. Furthermore, the large number of tests performed demands that caution be applied when interpreting the results. 
Table 4. Foods* (\% by weight) consumed/d according to their sugars content $\dagger$

\begin{tabular}{|c|c|c|c|c|c|c|}
\hline \multirow[b]{2}{*}{ Social class } & \multirow[b]{2}{*}{$n$} & \multirow{2}{*}{$\begin{array}{c}\text { Mean daily } \\
\text { weight of all } \\
\text { foods consumed } \\
\text { (g) }\end{array}$} & \multicolumn{4}{|c|}{ Sugars concentration of foods } \\
\hline & & & $\leqslant 1.0 \%$ & $1 \cdot 1-10 \cdot 0 \%$ & $10 \cdot 1-60.0 \%$ & $>60.0 \%$ \\
\hline \multicolumn{7}{|l|}{ Boys } \\
\hline High & 46 & 1801 & 24 & 55 & 20 & 1 \\
\hline Middle & 86 & 1789 & 24 & 57 & 18 & 1 \\
\hline Low & 52 & 1781 & 20 & 62 & 17 & 1 \\
\hline \multicolumn{7}{|l|}{ Girls } \\
\hline High & 39 & 1684 & 28 & 51 & 20 & 1 \\
\hline Middle & 86 & 1633 & 25 & 57 & 17 & 1 \\
\hline Low. & 66 & 1642 & 25 & 58 & 15 & 2 \\
\hline High sugars eaters $\ddagger$ & 42 & 2090 & 20 & 56 & 22 & 2 \\
\hline All subjects & 405 & 1713 & 24 & 57 & 18 & 1 \\
\hline
\end{tabular}

* A food is defined as any combination of items (as listed in food tables) consumed simultaneously, e.g. tea infusion plus milk plus sucrose is one food.

$\dagger$ The standard deviations were similar between the groups and were approximately: total weight of all foods, $287 ; \leqslant 1.0 \%$ sugars, $10 ; 1 \cdot 1-10.0 \%$ sugars, $11 ; 10 \cdot 1-60.0 \%$ sugars, $7 ;>60.0 \%$ sugars, 0.9 .

$\ddagger 10 \%$ of subjects (plus 'ties') with the highest sugars intake ( $>159 \cdot 5 \mathrm{~g} / \mathrm{d}$ ).

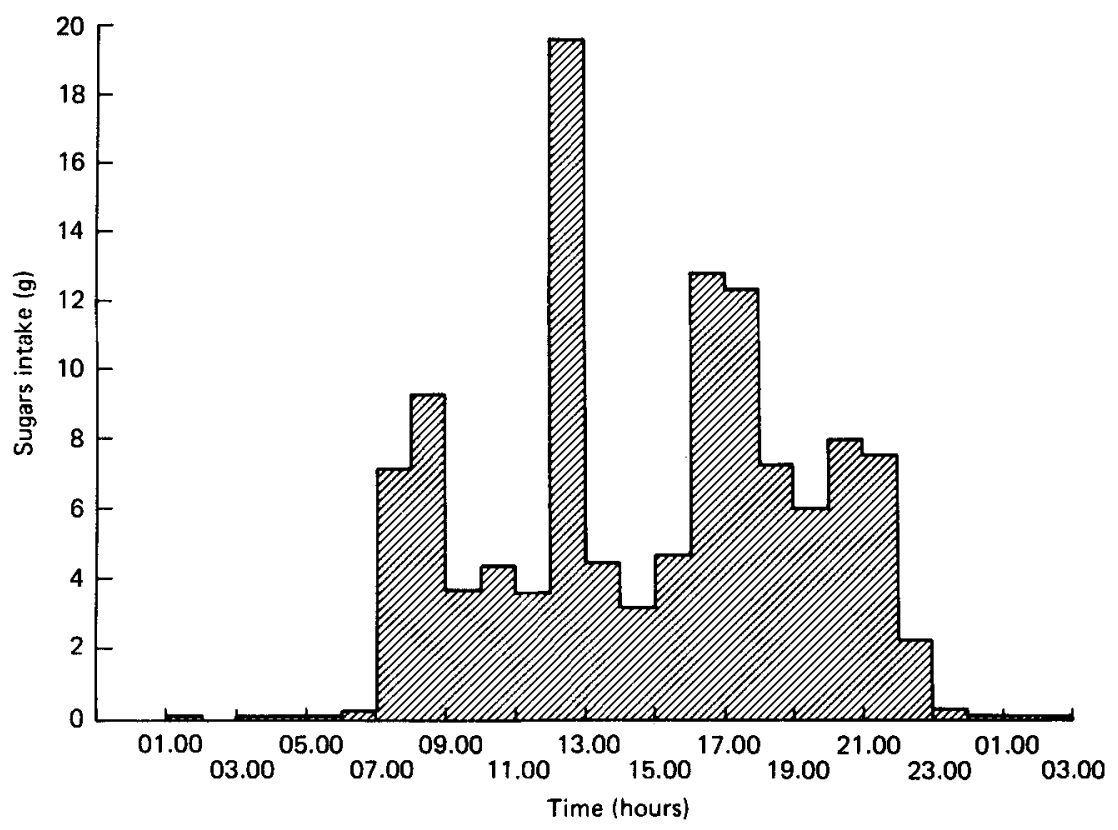

Fig. 2. Mean weight of sugars consumed for each hour of the day.

\section{DISCUSSION}

The diary-and-interview method proved an acceptable means of recording the dietary habits of a large number of adolescents over a long period of time. Five surveys of three consecutive days during a 2-year period gave, by analysis of variance (Goldstein, 1979), a reliability coefficient of 0.78 for estimating sugars intake enabling high and low sugars eaters to be differentiated (Hackett et al. 1983). 


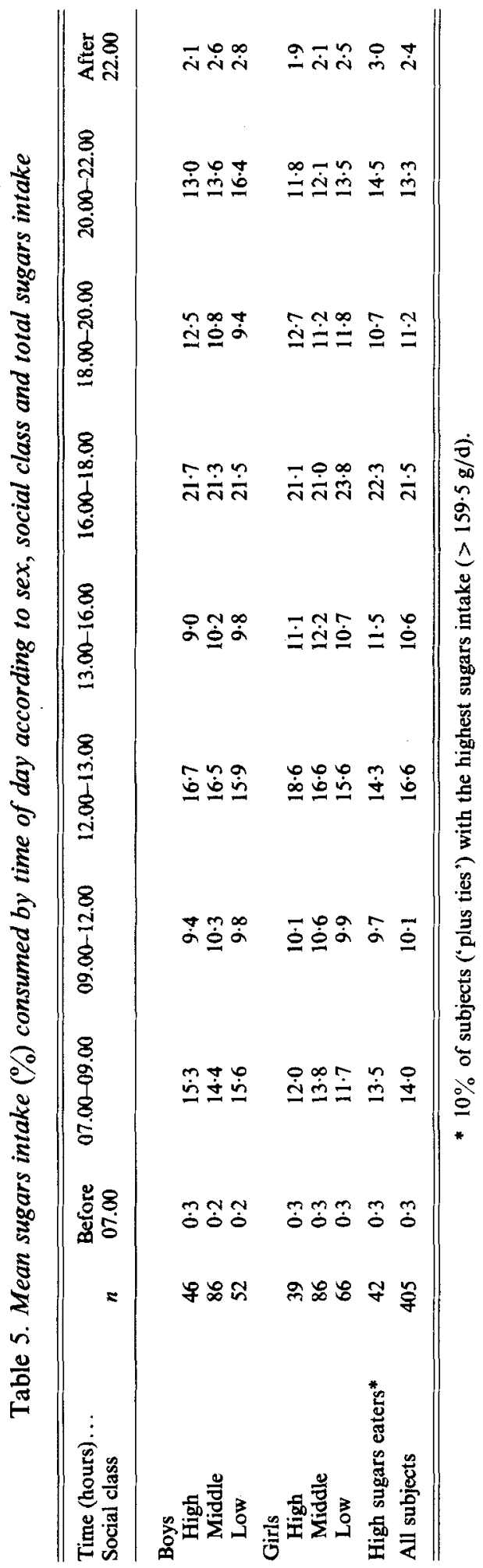


Table 6. Mean daily intake $(\%)$ of macronutrients and total sugars consumed as snacks*, according to sex

\begin{tabular}{lcc}
\hline \hline & Boys & Girls \\
\hline Energy & $42(4 \cdot 0 \mathrm{MJ})$ & $46(3.9 \mathrm{MJ})$ \\
Protein & 34 & 37 \\
Fat & 38 & 43 \\
Carbohydrate & 47 & 52 \\
Sugars & 62 & 65 \\
\hline \hline
\end{tabular}

* Defined as an intake having at least one of the following properties: (a) thought to make a minor contribution to the day's intake, $(b)$ eaten whilst engaged in some other activity, $(c)$ not eaten at recognized mealtimes or places.

Unfortunately, most recent British dietary surveys of adolescents do not report sugars intake in great detail. Cook et al. (1973) reported 'added sugar' intake only, which supplied approximately $18 \%$ of the energy intake of their sample of children aged 8-15 years (boys 113 and girls $90 \mathrm{~g}$ sugars/d). Likewise 'added sugars' was the only category reported by Darke \& Disselduff (1981) and supplied about $16 \%$ (boys 89 and girls $80 \mathrm{~g}$ sugars/d) of the energy intake of 10-11-year-olds from three English cities. The study of Widdowson (1947) carried out between 1935 and 1939 gives figures which apparently are for added sucrose only. The 11-, 12- and 13-year-old boys averaged 112 and the girls $89 \mathrm{~g}$ sucrose/d or 17 and $15 \%$ of their energy intakes respectively. Because it is unlikely that sugars occurring naturally have different cariogenicities than added sugars, the proportion of sugars added during processing and preparation were not calculated in the present study. The findings of the above studies (notwithstanding the differences in reporting sugars intake) are broadly in line with the present study suggesting that, over-all, the contribution of sugars intake has changed little over these years. Energy intakes, however, have changed markedly (Whitehead et al. 1982) and the type of sugars consumed and the way in which they are used have also changed (Bibby, 1975). Energy intake seems to be the major factor which determines the weight of sugars consumed. Although reliability was the same, the coefficient of variation of sugars intake was higher than that for energy, indicating that sugars intake was more variable, between children, than energy intake. Sugars intake was not strongly related to social class but there was a very small fall in the contribution of sugars to energy intake with increasing age (Table 1).

Durnin et al. (1957) reported the intake of twelve young Glaswegian women, mean age 20.5 years: sugar and preserves supplied $8.1 \%$ of their energy intake and sweets and chocolate $6.2 \%$, both figures very much higher than for the younger girls of the present study ( 4.4 and $4.0 \%$ respectively). No figures for total sugars intake were reported. These differences could be due to the differences in the age or locality of the subjects or to a change in habits over the last 25 years or to a combination of these factors.

The only investigation comparable to the present study is that conducted by Morgan \& Zabik (1981). They published an analysis of the sources of sugars intake of American children aged 5-12 years (total sugars intake for 11-12-year-olds $143 \mathrm{~g} / \mathrm{d}$ ). There are some striking differences between their findings and those of the present survey. Their largest source of sugars was from milk, which contributed $20 \%$ of the total, but in the present study only $13 \%$ of the sugars was lactose. Confectionery was the major component of the sugars intake of the English children (19\%) whereas the American children consumed only $8 \%$ of their sugars as candy plus sweet dairy products and frozen confectionery (a roughly analogous grouping). The Americans consumed over twice as much sugars as fruit (11\%) as the English $(5 \%)$, and more as sweetened beverages $(23 \%$, including fruit juices, 
compared with $14 \%$. Table sugar contributed less than $10 \%$ of the Americans' sugars intake but $17 \%$ of the English children's sugars intake. Although there were differences between the two surveys, both sets of eating habits were associated with a wide range of foods containing sugars and with high total sugars intake, and both surveys suggest frequent snacking.

The $25 \%$ of American children with the highest sugars intake consumed their sugars in various forms, but the groups of dessert sauces, fruits and fruit juices, and cakes, cookies, pies and other desserts, were judged to have the greatest impact, although the maximum difference was less than $3 \%$. The $10 \%$ of subjects with the highest sugars intake in the British survey did seem to have a slightly 'sweet tooth', consuming sugars over and above their high energy intakes. Unlike the American children, however, they did not show any preference for the form in which the sugars were consumed. Sugars were widely distributed throughout their diet, several (arbitrary) food categories contributing large proportions of the total and no one category contributing the major proportion. The sugars intakes were also widely spread throughout the day, although there was a preference for consuming sugars during the late afternoon and evening (48\%) and between main meals $(34.6 \%)$ (Table 5). These observations suggest that no one group of foods can be held responsible for high sugars consumption (although some individuals may have particular likes).

Most of the sugars intake $(62 \%)$ was consumed in the form of snacks. This is possibly a growing, relatively modern habit and is dentally undesirable (Report to the Nutrition Foundation, 1980). Dietary habits (the manner in which, as well as which particular foods are eaten) are clearly changing in line with changes in other behaviour patterns: working mothers, less formal intra-family relationships, greater independence of children, etc., and these factors should be considered when attempts are made to change dietary habits. Snacking is probably here to stay (Truswell \& Darnton-Hill, 1981); there is therefore a need for safe snacks to be developed. The criteria which define a safe snack are beyond the scope of this paper but should include foods of low sugars content.

Sugars were found to be a major dietary component, thoroughly dispersed throughout the diet and day's eating. Sugars are presently an integral part of the trend towards smaller, more frequent snack intakes and are introduced at a very early age (King, 1978). Even with ill-health (e.g. coronary heart disease) as a warning, dietary changes can be difficult to achieve, food intake being inexorably combined with other aspects of behaviour, habits and personality. If half of the soft drinks consumed were sweetened only artificially, sugars consumption would fall by approximately $7 \%$; if confectionery intake were halved, sugars intake would fall by about $10 \%$; if table sugar usage were halved, total sugars intake would decrease by approximately $8 \%$ and if sweet biscuit and cake consumption were halved, sugars intake would fall by $6 \%$. All these measures are realistic. If all were implemented, assuming that the foods substituted were sugars-free (it is possible that the consumption of some sugared foods, e.g. jam, would increase slightly), sugars intake could fall by $25-30 \%$ and a marked improvement in the figures for dental caries would be expected to occur. It is suggested that such changes would be assisted by the development of safe snacks, the modification of the composition of some existing products (particularly soft drinks and confectionery), effective food labelling and more health education campaigns.

This research was supported by an M.R.C. Project Grant.

\section{REFERENCES}

Bailey, N. T. J. (1981). Statistical Methods in Biology, 2nd ed. London: Hodder and Stoughton.

Bibby, B. G. (1975). Journal of the American Dental Association 90, 121-132.

Chambers, D. W. (1981). In Diet, Nutrition and Dentistry, pp. 127-138 [P. M. Randolph and C. I. Dennison, editors]. St Louis, Toronto, London: The C.V. Mosby Company. 
Cook, J., Altman, D. G., Moore, D. M. C., Topp, S. G., Holland, W. W. \& Elliot, A. (1973). British Journal of Preventive and Social Medicine 27, 91-99.

Darke, S. J. \& Disselduff, M. M. (1981). In Department of Health and Social Security, Sub-Committee on Nutritional Surveillance: Second Report. Committee on Medical Aspects of Food Policy, pp. 111-130. London: H.M. Stationery Office.

Department of Health and Social Security (1978). Prevention and Health, Eating for Health, p. 74. London: H.M. Stationery Office.

Durnin, J. V. G. A., Blake, E. C. \& Brockway, J. M. (1957), British Journal of Nutrition 11, 85-94.

Goldstein, H. (1979). The Design and Analysis of Longitudinal Studies, pp. 129-137. London: Academic Press.

Hackett, A. F., Rugg-Gunn, A. J. \& Appleton, D. R. (1983). Human Nutrition: Applied Nutrition 37A, $293-300$.

King, J. (1978). Community Dentistry and Oral Epidemiology 6, 47-52.

Morgan, K. J. \& Zabik, M. E. (1981). American Journal of Clinical Nutrition 34, 404-413.

Paul, A. A. \& Southgate, D. A. T. (1978). McCance and Widdowson's The Composition of Foods, 4th ed. London: H.M. Stationery Office.

Registrar General (1970). Classification of Occupations 1970. Office of Population Censuses and Surveys. London: H.M. Stationery Office.

Report to the Nutrition Foundation (1980). International Advisory Group on the Relationship Between Diet, Nutrition and Dental Caries. Washington DC: The Nutrition Foundation.

Royal College of Physicians (1983). Journal of the Royal College of Physicians, London 17, 5-65.

Truswell, A. S. \& Darnton-Hill, I. (1981). Nutrition Reviews 39, 73-88.

United States Senate (1977). Dietary Goals of the United States, 2nd ed. Washington DC: US Government Printing House.

Whitehead, R. G., Paul, A. A. \& Cole, T. J. (1982). Human Nutrition: Applied Nutrition 36A, 57-62.

Widdowson, E. M. (1947). Medical Research Council, Special Report Series no. 259, pp. 64-81 London: H.M. Stationery Office. 